\title{
Polystyrene-coated Interdigitated Microelectrode Array to Detect Free Chlorine towards IoT Applications
}

\author{
Yang LiU,* Yuchen Liang, ${ }^{*}$ Leo Xue, ${ }^{* * *}$ Ran LiU,* Jun TAO,* Dian Zhou, $* * *$ Xuan Zeng, ${ }^{* \dagger}$ and \\ Walter $\mathbf{H u}^{*, * * \dagger}$ \\ *ASIC and System State-key Laboratory Microelectronics Department, Fudan University, Shanghai 201203, \\ China \\ **Electrical and Computer Engineering Department, University of Texas at Dallas, Richardson, TX 75080 , \\ USA \\ ***Zhangjiagang One-chip Biotechnology Co., Ltd, Suzhou 215614, China
}

\begin{abstract}
We apply interdigitated microelectrode array (IDA) sensors for water quality monitoring. IDA sensors with an ion-sensitive coating show higher sensitivity of about $600 \mathrm{mV}$ with the hypochlorite ion concentration increasing from 0 to $10 \mathrm{ppm}$ more than the traditional sensing method. The response mechanism and selectivity have been studied. Several material components that affect the sensing process were explored. Coupling agents and plasticizer were introduced into the coating material to improve the coating material quality and its adhesion to the electrodes. The stability/repeatability and linearity have been significantly improved.
\end{abstract}

Keywords IDA, sensor, free chlorine, sensitivity, stability

(Received October 16, 2018; Accepted December 18, 2018; Advance Publication Released Online by J-STAGE December 28, 2018)

\section{Introduction}

In recent years, how to monitor water quality in real time has drawn much attention from both regulatory agencies and researchers. One popular method is to use a sensor network in the setting of Internet of Things (IoT) to detect water quality factors and share the data using the internet. ${ }^{1}$ There are six groups of contaminants in water: microorganisms, disinfectants, disinfection byproducts, inorganic chemicals, organic chemicals and radionuclides. ${ }^{2}$ Chlorine is commonly used for disinfection due to its strong oxidizing property. It is widely applied for drinking water, ${ }^{3}$ swimming pools, waste water, as well as bleaching and other manufacturing processes. ${ }^{4}$ Free chlorine is defined as the sum of hypochlorous acid $(\mathrm{HClO})$, hypochlorite ion $\left(\mathrm{ClO}^{-}\right)$and dissolved chlorine gas in the water, ${ }^{5}$ since they all maintain a strong oxidizing property. The concentration of free chlorine in water is a commonly used index factor for the disinfectant level in drinking and swimming pool water. If the level is too low, the disinfection function will be insufficient. If it is too high, the risk of cancer due to long-time exposure will be largely increased. The United States Environmental Protection Agency (US EPA) recommends a minimum free chlorine concentration of $1 \mathrm{ppm}$ and a maximum level of $4 \mathrm{ppm}$ to maintain both safety and proper disinfection functions. ${ }^{6}$ The World Health Organization (WHO) "Drinking-water Quality Instructions" set an upper limit for chlorine at $5 \mathrm{ppm}$. Therefore,

Y. Liu and Y. Liang contributed equally to this work.

${ }^{\dagger}$ To whom correspondence should be addressed.

E-mail: walter.hu@utdallas.edu (W. H.); xzeng@fudan.edu.cn (X. Z.) a precise detection method for the free chlorine concentration is required.

Until now, several different methods have been developed for precisely detecting free chlorine in tap water. ${ }^{7}$ Among them, the colorimetric method ${ }^{8}$ is the most commonly used. However, apart from its accuracy, the color reagent is not always safe, and the procedure of this method is not suitable for continuous monitoring. There are some other analytical methods, such as iodometric titration, ${ }^{9}$ optical methods ${ }^{10}$ or electrochemical techniques. ${ }^{11}$ Among them, electrochemical techniques are versatile and can provide several advantages, such as low-cost, low power consumption, fast and reproducible data acquisition and a small form factor. ${ }^{12}$ However, most of the current electrochemical methods use electrodes with a gas permeable membrane that requires an internal solution, and therefore contains a complicated sensor structure and requires periodically maintenance, such as a re-fill standard solution and a replace membrane. As a result, they are incompatible with miniaturized and low-power devices required for IoT applications.

In 1992, a new electrical detection method was first reported by Motomizu et al. Through potentiometric measurements with an ion-selective layer coated electrode (ISE), an in situ linear response of the electrode potential to the free chlorine concentration with a $0.5-\mathrm{ppm}$ resolution was achieved. ${ }^{13}$ However, the stability and reversibility of the electrode deteriorates rapidly due to a blocking effect of the polyvinyl chloride (PVC) coating layer and the formation of a water layer between the electrode and the coating layer. Subsequently, many ISEs, such as $\mathrm{Pb}[\mathrm{II}]-\mathrm{ISEs},{ }^{14}$ potassium iodide redox electrodes, ${ }^{15} \mathrm{Fe}(\mathrm{III}) / \mathrm{Fe}(\mathrm{II})$ redox ISE $^{16}$ and acetylcholine sensitive enzyme ISE, ${ }^{17}$ have been reported for free chlorine 


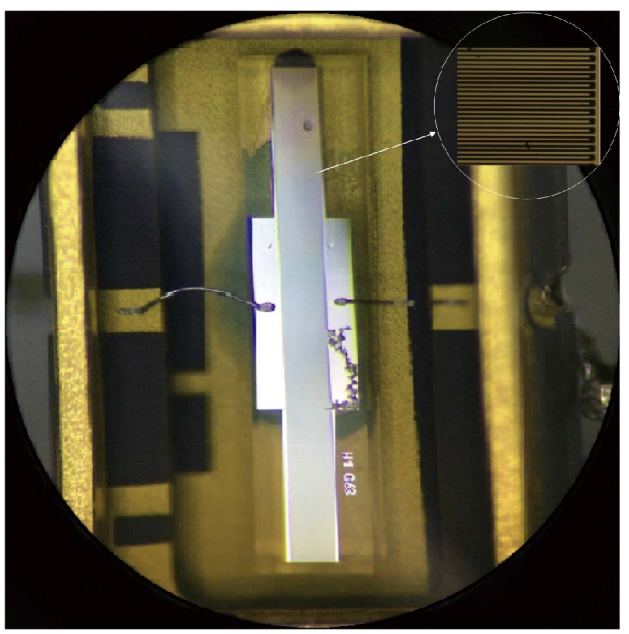

Fig. 1 Partial structure of the IDA device and enlarged image of the IDA structure. The height of each electrode is $0.3 \mu \mathrm{m}$ and the gap between is $2.28 \mu \mathrm{m}$.

detection. These methods cost less, and the response is quicker. The preparation and operation processes are simpler. However, it is difficult for conventional ISEs to maintain accuracy with their size being miniaturized. Therefore, a new type of ISE that is both small and accuracte is required for low-power IoT devices.

Here, we introduce interdigitated array (IDA) electrodes for chlorine detection. IDA electrodes are known for their high sensitivity, small form factor, and rapid response. ${ }^{18}$ They are much cheaper compared to traditional electrodes, since they can be manufactured in large scale using semiconductor fabrication processes. IDA has already demonstrated its advantages in fields including the environmental monitoring, aerospace industries and automotive, chemical and biochemical processing. ${ }^{19}$ Here, we bring up the idea of combining IDA electrodes with the conventional ion selective layer (ISL) preparation process. In this study, the ISL consists of polystyrene (PS) and zephiran chloride $(\mathrm{ZePhCl})$. Polyethylene ferrocene (PVFc) was then introduced into the PS membrane. The device sensitivity, selectivity and stability were tested and the mechanism for free chlorine potentiometric measurement was discussed. Results indicated that IDA electrodes with an ISE membrane can reach a potential increase of nearly $600 \mathrm{mV}$ with the $\mathrm{ClO}^{-}$concentration increasing from 0 to $10 \mathrm{ppm}$. With coupling agents and plasticizer employed into the membrane, the $\mathrm{ClO}^{-}$detection achieved high sensitivity and good linearity.

\section{Experimental}

\section{Electrode preparation}

The IDA device used is shown in Fig. 1. It consists of 302 interdigitated aluminum fingers that sit on a silicon dioxide substrate; each electrode is $2.69 \mu \mathrm{m}$ in width and $265.5 \mu \mathrm{m}$ in length and the IDA part is connected to the outside test circuit through wire bonding.

To prevent corrosion of the aluminum IDA electrode by the solution, $100 \mathrm{~nm} \mathrm{HfO}_{2}$ is coated on top of the device through atomic layer deposition (ALD) at $250^{\circ} \mathrm{C}$.

The electrode coating material is a PS-ZephCl-PVFc mixture. $\mathrm{PS}, \mathrm{ZephCl}$ and $\mathrm{PVFc}$ are dissolved in $10 \mathrm{~mL}$ of tetrahydrofuran (THF) with a ratio of $2: 1: 1$. To study the coating material property, a coating material without PVFc was prepared too.

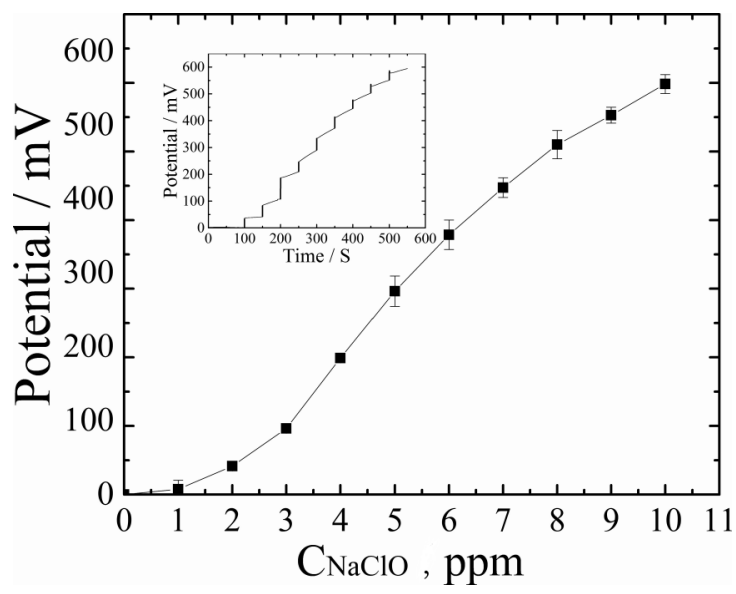

Fig. 2 Device potential dependence of PS-ZephCl-PVFc-IDA electrode on $\mathrm{NaClO}$ concentration. The inset shows the variation of electrode potential response with time during each measurement.

The coating membrane was casted by dripping the coating material onto the device surface in a nitrogen glove box and followed by drying under a nitrogen atmosphere for $2 \mathrm{~h}$.

\section{Potentiometric measurements}

PS powder, $\mathrm{PVFc}$, THF, $\mathrm{Na}_{2} \mathrm{SO}_{4}, \mathrm{Na}_{2} \mathrm{CO}_{3}$, and $\mathrm{ZephCl}$ are all analytical reagents purchased from Aladdin Industrial Co., Ltd. (Shanghai, China). All solutions were prepared with deionized water (Millipore, $18.25 \mathrm{M} \Omega \cdot \mathrm{cm}$ ). A series of solutions with a free chlorine concentration from $0-10 \mathrm{mg} \mathrm{L}^{-1}$ (ppm) was prepared by dissolving the commercial sodium hypochlorite solution in the deionized water (DI water); iodometric titration was used to determine the actual hypochlorite concentration before each test, considering that sodium hypochlorite can easily decompose.

Before each measurement, the electrode was rinsed with DI water for $30 \mathrm{~min}$. All measurements were conducted at room temperature. The open-circuit potential $\left(V_{\mathrm{oc}}\right)$ was recorded using an electrochemical workstation to measure the potential response of the coated IDA electrodes with varied free chlorine concentrations. A $25-\mathrm{mV}$ bias voltage was applied with the open circuit potential test mode.

\section{Results and Discussion}

\section{Potential response behavior}

As shown in Fig. 2, the potential response (without calculating the initial bias voltage) increases monotonically as the free chlorine concentration increases. The inset graph in Fig. 2 shows the raw data of the potential response with time during changing solutions. The consuming response time is recorded when the potential increase is less than $0.02 \mathrm{mV} \mathrm{s}^{-1}$. As shown in the graph, the potential response can reach a "quasi-steady state" in less than $50 \mathrm{~s}$ which is considered to be a fast respond speed. The positive correlation between the electrode potential of a PVC-ZephCl-Fc membrane coated glassy carbon electrode and the $\mathrm{ClO}^{-}$concentration was previously reported by Dai et al. ${ }^{20}$ In that study, the electrode potential was linearly proportional to the logarithm of the $\mathrm{ClO}^{-}$concentration, which followed the Nernst equation. Our result shows a total potential increase of nearly $600 \mathrm{mV}$ with the $\mathrm{ClO}^{-}$concentration increasing from 0 to $10 \mathrm{ppm}$, showing a much higher sensitivity. 


\section{Theoretical analysis of response mechanism}

We suspect that the PS in the coating layer is mainly used to form the membrane structure. The $\mathrm{ZephCl}$ can provide ionexchange sites (both $\mathrm{Zeph}^{+}$and $\mathrm{Cl}^{-}$). The $\mathrm{Cl}^{-}$in the membrane is free, and it can thus exchange with the $\mathrm{ClO}^{-}$in the solution In the meanwhile, the $\mathrm{Zeph}^{+}$, which is fixed in the membrane provides a stronger attraction to $\mathrm{ClO}^{-}$compared to $\mathrm{Cl}^{-}$due to the larger size of $\mathrm{ClO}^{-} .{ }^{21}$ Consequently, the ion-exchange reaction between the $\mathrm{Cl}^{-}$in membrane and the $\mathrm{ClO}^{-}$in solution induces a diffusion of $\mathrm{ClO}^{-}$towards the coating layer. The ferrocene in PVFc can be oxidized by $\mathrm{ClO}^{-}$and form $\mathrm{Fc}^{+}$, which can further facilitate $\mathrm{ClO}^{-}$diffusion into the membrane in order to maintain charge neutralization and accelerate the diffusion process. ${ }^{22}$ The ion exchange between the solution and the membrane can be expressed as:

$$
\begin{aligned}
& \mathrm{ClO}^{-}{ }_{\mathrm{sln}}+\mathrm{Cl}^{-}{ }_{\mathrm{m}} \rightleftharpoons \mathrm{ClO}^{-}{ }_{\mathrm{m}}+\mathrm{Cl}^{-}{ }_{\mathrm{sln}} \\
& \mathrm{ClO}^{-}+\mathrm{H}_{2} \mathrm{O} \rightleftharpoons \mathrm{HClO}+\mathrm{OH}^{-} \\
& K_{1}=\frac{\left[\mathrm{ClO}_{\mathrm{m}}^{-}\right]\left[\mathrm{Cl}_{\mathrm{sin}}^{-}\right]}{\left[\mathrm{ClO}_{\mathrm{sin}}^{-}\right]\left[\mathrm{Cl}_{\mathrm{m}}^{-}\right]} \\
& 2 \mathrm{Fc}+\mathrm{ClO}^{-}{ }_{\mathrm{m}}+\mathrm{H}_{2} \mathrm{O} \rightleftharpoons 2 \mathrm{Fc}^{+}+\mathrm{Cl}^{-}{ }_{\mathrm{m}}+2 \mathrm{OH}^{-}, \\
& K_{2}=\frac{\left[\mathrm{Cl}_{\mathrm{m}}^{-}\right]\left[\mathrm{Fc}^{+}\right]^{2}\left[\mathrm{OH}^{-}\right]^{2}}{\left[\mathrm{ClO}_{\mathrm{m}}^{-}\right][\mathrm{Fc}]^{2}}, \\
& \frac{\left[\mathrm{Fc}^{+}\right]^{2}}{[\mathrm{Fc}]^{2}}=\frac{\left[\mathrm{Fc}^{+}\right]^{2}}{\left(a-\left[\mathrm{Fc}^{+}\right]\right)^{2}}=K_{2} \frac{\left[\mathrm{ClO}_{\mathrm{m}}^{-}\right]}{\left[\mathrm{Cl}_{\mathrm{m}}^{-}\right]\left[\mathrm{OH}^{-}\right]^{2}}=K_{1} K_{2} \frac{\left[\mathrm{ClO}_{\text {sln }}^{-}\right]}{\left[\mathrm{Cl}_{\text {sln }}^{-}\right]\left[\mathrm{OH}^{-}\right]^{2}},
\end{aligned}
$$

$$
\begin{aligned}
& {\left[\mathrm{Fc}^{+}\right]=\frac{a}{1+1 / \sqrt{K\left[\mathrm{ClO}^{-}{ }_{\mathrm{sin}}\right]}},} \\
& K=\frac{K_{1} K_{2}}{\left[\mathrm{Cl}_{\mathrm{sln}}^{-}\right]\left[\mathrm{OH}^{-}\right]^{2}} .
\end{aligned}
$$

Here, the subscripts sln and $m$ represent the ions in solution and the membrane. The equilibrium between the $\mathrm{ClO}^{-}$and the $\mathrm{Cl}^{-}$in the tested solutions can be established as Eq. (2). Also, the equilibrium constant, $K_{1}$, can be described as Eq. (3), the Fc in $\mathrm{PVFc}$ can be oxidized by $\mathrm{ClO}^{-}$and the reaction is given by Eq. (4). Then, the corresponding equilibrium constant, $K_{2}$, is expressed as Eq. (5). Combining Eqs. (3) and (5), we have Eq. (6) and $a$ is the total Fc concentration in the coating layer. Finally, the oxidized $\mathrm{Fc}$ concentration can be described as Eq. (7). In this case the final reaction equilibrium constant, $K$, can be expressed as Eq. (8).

Based on the previous description and analysis, IDA is coated with $100 \mathrm{~nm} \mathrm{HfO}_{2}$, which can be treated as a capacitor around the electrodes. The initial bias voltage causes a nonuniform distribution of the $\mathrm{ClO}^{-}$at positive and negative charged electrodes, which results in different concentrations of $\mathrm{Fc}^{+}$. The potential change that we measure is the voltage change across the positive and negative electrodes (Fig. S1, Supporting Information). The change of the $\mathrm{ClO}^{-}$concentration in the solution will induce a concentration change of $\mathrm{Fc}^{+}$near the electrode surface. With the continuously accumulated $\mathrm{Fc}^{+}$in the membrane, the capacitor will be charged, and an electrode potential shift occurs. Eventually, the electrode potential shows positive, correlated with the $\mathrm{ClO}^{-}$concentration in the solution through $\mathrm{Fc}^{+}$.

Since all of the capacitors are connected in series, there will be the same surface charge change on each capacitor (Fig. S1).
Due to small $C_{\text {ox }}, C_{\text {total }}$ is much smaller than $C_{\mathrm{dl}}$, and then for the same amount of surface charge, $\Delta V_{\text {total }}$ would be much larger than $\Delta V_{\mathrm{dl}}$, exceeding the Nernst limit. This effect is similar in nature to recently observed steric effects of a smaller surface capacitance causing a signal beyond the Nernst limits. ${ }^{23}$ The potential change across the double layer may follow the Nernst equation if the reaction is a single step. However, in our sensor structure, because of the existence of the phase transfer catalyst, $\mathrm{ZephCl}$, there is one extra step of ion transfer. The quaternary ammonium cation in the $\mathrm{Zeph}^{+}$is hydrophilic, and the benzene is hydrophobic. Therefore, it can help transfer the $\mathrm{ClO}^{-}$ion through the water-organic interface. With the change of the $\mathrm{Fc}^{+}$ concentration in the coating layer, the equilibrium constant of Eq. (1) will also change. In this case, the two-step process can not be simply described by the Nernst equation, and therefore the measured potential is not linearly proportional to the logarithm of the $\mathrm{ClO}^{-}$concentration.

Meanwhile, coating membranes without ZephCl or PVFc were prepared to verify the function of $\mathrm{ZephCl}$ and PVFc. The same potentiometric tests were performed, but no monotonic or effective potential shift was observed with a varied $\mathrm{NaClO}$ concentration (Fig. S2, Supporting Information). This indicates that the diffusion and reduction of $\mathrm{ClO}^{-}$cannot happen without $\mathrm{PVFc}$ or ZephCl in the coating material.

Scanning electron microscope images of ISE membranes with and without $\mathrm{ZephCl}$ show that there are microscopic pores in the membrane containing ZephCl, and almost no pore in the membrane without ZephCl (Fig. S3, Supporting Information). We believe that these pores increase the inner surface area of membrane, which facilitates ion exchange between the solution and the coating membrane.

Pool water possibly contains anions, such as $\mathrm{Cl}^{-}, \mathrm{SO}_{4}{ }^{2-}$ and $\mathrm{CO}_{3}{ }^{2-}$, and common cations, such as $\mathrm{Na}^{+}, \mathrm{K}^{+}$. Therefore, the interference from these ions should be evaluated. As shown in Fig. 3, the non-monotonic potential change is smaller than $50 \mathrm{mV}$ for an interfering ion concentration changing from 1 to $10 \mathrm{ppm}$, which is much smaller compared to that of the $\mathrm{ClO}^{-}$. Thus, the interference of these ions can be considered to be relatively small.

\section{Stability of the electrode and improvement of coating material}

To evaluate the stability of the device, the same test was repeated each day after the first test. After each test, the samples were soaked in DI water for $30 \mathrm{~min}$, and then dried to store. As shown in Fig. 4, the sensing curve shifts each day and the sensitivity $\left(\mathrm{mV} \mathrm{ppm}^{-1}\right)$ at low concentrations of the electrode also decays. This indicates that the performance of the electrode starts to deteriorate. From the literature, this phenomenon is likely caused by water diffusing into the coating layer and shedding the coating layer from electrode. It is most likely due to the polar nature of PS and the hydrophilic nature of ZephCl. ${ }^{24}$

After immersing the device in the test solution for about 10 days, the coating membrane showed that cracks formed on the surface. Therefore, it is critical to improve the film-electrode adhesion and the coating material quality. To prevent deterioration, a plasticizer was added into the coating layer. The morphology of the coating membranes with different amounts of plasticizer after immersing in the test solution for 10 days shows that a higher plasticizer concentration seems to yield more stable films (Fig. S4, Supporting Information).

Moreover, coupling agents are widely employed as the surface modifier to link polymers, bio-macromolecules, and other species to the surface of materials. Here, 3-aminopropyltriethoxysilane (APTES) ${ }^{25}$ is used to form a molecular layer on the IDA surface to modify the interface between the electrode 


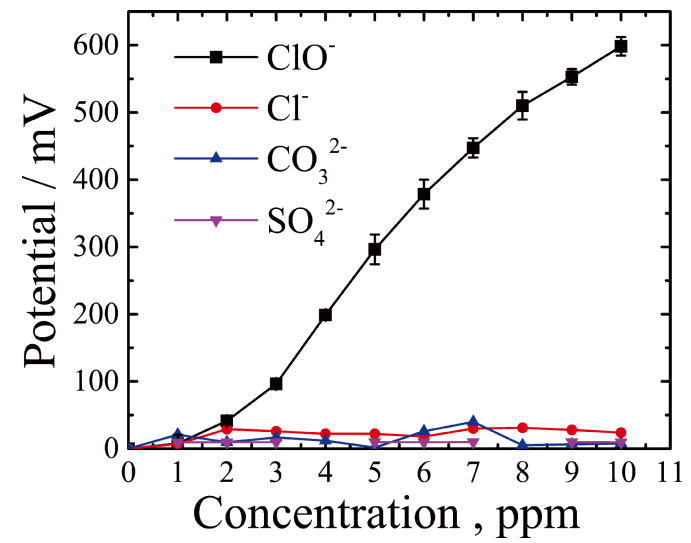

Fig. 3 Potential response to the concentration of tested ions in the solution.

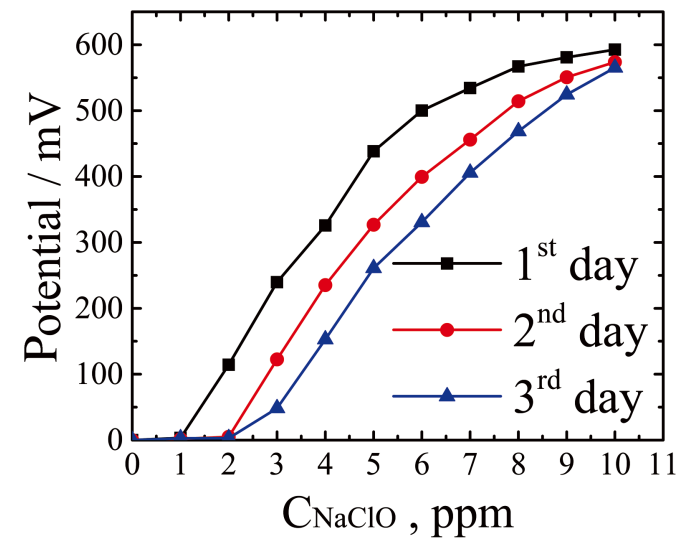

Fig. 4 Potential variation of the same electrode measured in 3 continuous days. The sensing curve shifts and the electrode decays.
(A)

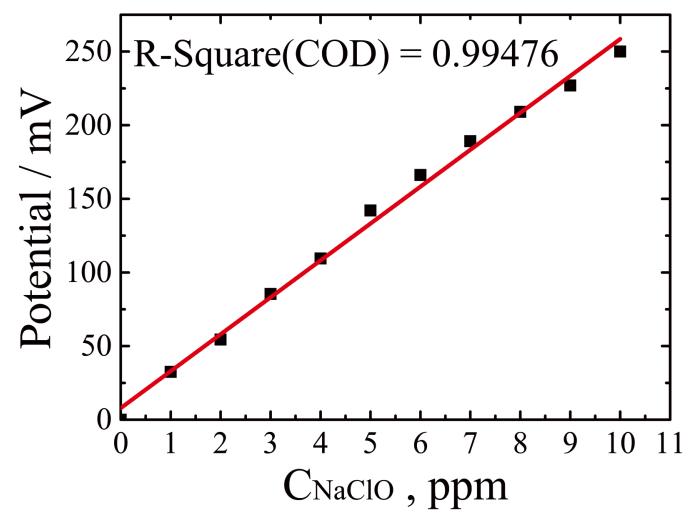

(B)

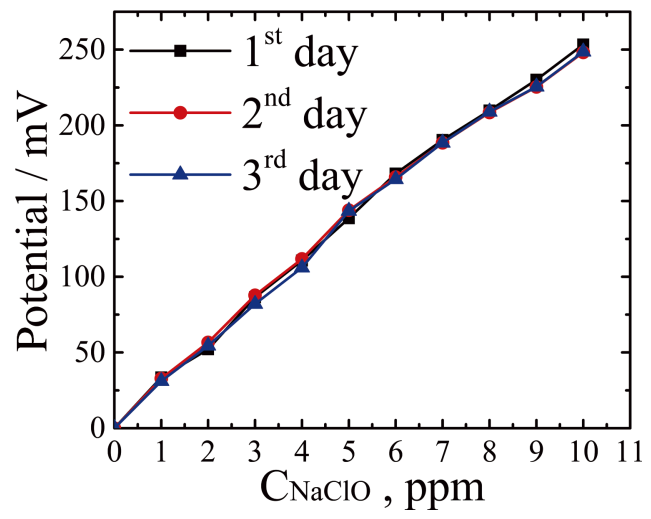

Fig. 5 Potential response of the modified PS-ZephCl-PVFc-IDA electrode with APTES surface coating and added plasticizer into the coating materials. R-Square of linear fitting curve about 0.99 is observed (A) and the device stability is much improved (B) compared with Fig. 4.

and the coating material and to improve the film-electrode adhesion. The electrode surface is first cleaned with anhydrous ethanol, and then a molecular layer is formed by immersing electrode surface in the APTES solution in a glove box with a humidity of $25 \%$ for $30 \mathrm{~min}$. For the new devices, $0.5 \%$ plasticizer A608-2 (King Technology Co., Ltd., Shenzhen, China) is added to the ISE membrane to improve the quality of the coating material.

The potential response of the modified electrode is shown in Fig. 5(A). The electrode potential is positively correlated with the $\mathrm{ClO}^{-}$concentration in the solution. Moreover, a better linearity with an R-Square of a linear fitting curve of about 0.99 is observed. This result shows that the total potential variation is about $200 \mathrm{mV}$, and an average sensitivity of about $20 \mathrm{mV} \mathrm{ppm}{ }^{-1}$ occurs. Figure 5(B) is the stability test results. In the first 3 days, the characteristic and sensitivity are almost the same. Compared to the results without the coupling agents and the plasticizer (Figs. 2 and 4), although the sensitivity is smaller, the device stability and linearity are much improved. The sensitivity of $20 \mathrm{mV} \mathrm{ppm}^{-1}$ is still an order of magnitude higher than other similar free chlorine sensors. ${ }^{26}$ Also, the linear relationship means better sensitivity at low concentration, especially at $1 \mathrm{ppm}$, which has practical meaning in an actual swimming pool water environment.

It is noted that the sensitivity of this modified electrode seems to be lower than a non-modified electrode compared to Fig. 2. One explanation could be that, since IDA can be treated as a capacitor around the electrodes based on the previous description, an APTES molecular layer on the IDA surface reduces the capacitance of the modified electrode. Also, the plasticizer content cut the effective component of the ISL membrane. Furthermore, it is highly possible that the plasticizer added into the coating layer improves the membrane stability and makes the membrane more compact, which just restrains the ion exchange between the solution and the coating membrane. Although the $\mathrm{NH}_{3}{ }^{+}$groups of the APTES molecules can attract not only $\mathrm{ClO}^{-}$, but also $\mathrm{Cl}^{-}$, which is abundant in tap water. However, $\mathrm{Cl}^{-}$, itself, will not react with $\mathrm{Fc}$ and therefore would not interfere with the detection selectivity, as we observed.

A possible reason for this linear curve is the influence of the coupling agent APTES. Without the APTES coating, the $\mathrm{HfO}_{2}$ coated electrode surface would be electrically neutral. According to the site binding model, ${ }^{27}$ the oxide surface can de-protonate in the basic $\mathrm{pH}$ range and acquire negative charges. In the basic environment, the $\mathrm{HfO}_{2}$ surface is negatively charged based on 
the $\mathrm{p} K_{\mathrm{a}}$ of the $\mathrm{HfO}_{2}$ surface. Therefore, at low $\mathrm{ClO}^{-}$ concentrations, the $\mathrm{HfO}_{2}$ surface will not be able to facilitate $\mathrm{ClO}^{-}$diffusing into the coating material. This also helps to explain the low sensitivity below 2 ppm, as shown in Fig. 2. It is known that the thermal oxide surface can be functionalized by self-assembly monolayers (SAM), such as APTES, which carries the amine $\left(\mathrm{NH}_{2}\right)$ group in the molecular structure. The dissociation constant of APTES is reported to be 10 from previous literature, ${ }^{28}$ which means that the amine group can protonate to $\mathrm{NH}_{3}{ }^{+}$in the basic condition. Therefore, even though the $\mathrm{HfO}_{2}$ surface remains electrically negative in the basic condition, the APTES on the surface can still facilitate $\mathrm{ClO}^{-}$ions diffusing into the coating material to compensate the initial low concentrations of $\left[\mathrm{Fc}^{+}\right]$. In this case, the potential response as well as the slope of the sensitivity curve in basic condition is enhanced. Then, with the increase of the $\mathrm{ClO}^{-}$ concentration, higher $\mathrm{pH}$ values cause further negative charges on the $\mathrm{HfO}_{2}$ surface and electrically neutral of APTES, restraining the diffusion of $\mathrm{ClO}^{-}$into the coating material and decreasing the sensitivity curve slope. Consequently, a linear potential response in the whole detection range is observed.

\section{Conclusions}

In this work, sensitive and selective sensors based on micro-IDA electrodes have been developed for the detection of residue chlorine $\left(\mathrm{ClO}^{-}\right)$. The ISL material of PS-ZephCl-PVFc-IDA is coated on the sensor devices, showing a monotonic potential response with varied TRC concentrations from 0 to $10 \mathrm{ppm}$. A large potential response of about $600 \mathrm{mV}$ occurs for $10 \mathrm{ppm}$ or $60 \mathrm{mV} \mathrm{ppm}^{-1}$, demonstrating a much higher sensitivity compared to the traditional sensing methods. The potential response mechanism is also explored. Control experiments show that $\mathrm{ZephCl}$ can provide ion-exchange sites, and $\mathrm{Fc}$ oxidization by $\mathrm{ClO}^{-}$can charge the IDA capacitor. ISE materials lacking $\mathrm{Fc}$ and $\mathrm{ZephCl}$ show irregular signals. The device also shows high selectivity to common ions in pool water, i.e. $\mathrm{Cl}^{-}$, $\mathrm{SO}_{4}{ }^{2-}$ and $\mathrm{CO}_{3}{ }^{2-}$.

The stability of the device is evaluated by observing the sensing curve shifts for several days. It shows that sensitivity at low $\mathrm{ClO}^{-}$concentrations decays with time going on. To improve the film-electrode adhesion and the coating material quality, coupling agents APTES is used to modify the $\mathrm{HfO}_{2}$ coated electrode surface, and a plasticizer is added into the ISL material, respectively. Although the sensitivity reduces to $200 \mathrm{mV}$ with a TRC concentration range of 0 to $10 \mathrm{ppm}$ or

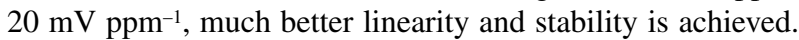

We believe that the micro-IDA chip with the improved ISE membrane shows a strong potential for residue chlorine detection for applications in pool water monitoring, etc. It has advantages of small size, low cost, rapid response, and low power consumption, which is particularly suitable for Internet of Things.

\section{Acknowledgements}

This research was supported partly by National Natural Science Foundation of China (NSFC) research projects 61628402, partly by National Key Research and Development Program of China 2016YFB0201304, and partly by National Natural Science Foundation of China (NSFC) research projects 61574046, $61574044,61774045$.

\section{Supporting Information}

This material is available free of charge on the Web at http:// www.jsac.or.jp/analsci/.

\section{References}

1. A. Al-Fuqaha, M. Guizani, M. Mohammadi, M. Aledhari, and M. Ayyash, IEEE Commun. Surv. Tutorials, 2015, 17, 2347.

2. USEPA, "National Primary Drinking Water RegulationsDisinfectans and Disinfection Byproducts", 1998.

3. F. Kodera, M. Umeda, and A. Yamada, Anal. Chim. Acta, 2005, 537, 293.

4. V. Wigotsky, Society of Plastics Engineers Inc., 1995, Vol. 51, No. 2.

5. F. Kodera, S. Y. Kishioka, M. Umeda, and A. Yamada, Jpn. J. Appl. Phys., 2004, 43, L913.

6. C. N. Ibeto, N. F. Oparaku, and C. G. Okpara, J. Environ. Sci. Technol., 2010, 3, 226.

7. F. W. O. Gilcreas, Health Lab. Sci., 1967, 4, 137.

8. L. Moberg and B. Karlberg, Anal. Chim. Acta, 2000, 407, 127.

9. J. H. Carpenter, C. A. Moore, and D. L. Macalady, Environ. Sci. Technol., 1977, 11, 992.

10. M. Belz, W. J. O. Boyle, K.-F. Klein, and K. T. V. Grattan, Sens. Actuators, B, 1997, 39, 380.

11. J. Jin, Y. Suzuki, N. Ishikawa, and T. Takeuchi, Anal. Sci., 2004, 20, 205.

12. R. Olivé-Monllau, J. Orozco, C. Fernández-Sánchez, M. Baeza, J. Bartrolí, C. Jimenez-Jorquera, and F. Céspedes, Talanta, 2009, 77, 1739.

13. S. Motomizu and T. Yoden, Anal. Chim. Acta, 1992, 261, 461.

14. A. Sakai, A. Hemmi, H. Hachiya, F. Kobayashi, S. Ito, Y. Asano, T. Imato, Y. Fushinuki, and I. Taniguchi, Talanta, 1998, 45, 575

15. K. D. Brown and G. A. Parker, Analyst, 1982, 107, 1510.

16. N. Ishibashi, T. Imato, H. Ohura, and S. Yamasaki, Anal. Chim. Acta, 1988, 214, 349.

17. A. P. Soldatkin, D. V. Gorchkov, C. Martelet, and N. Jaffrezic-Renault, Sens. Actuators, B, 1997, 43, 99.

18. M. Varshney and Y. Li, Biosens. Bioelectron., 2009, 24, 2951.

19. J. Lin and L. Obermeier, Sens. Actuators, B, 1991, 5, 223.

20. X.-H. Dai, J. Zhang, X.-J. Pang, J.-P. Zhou, G.-Z. Liu, and S.-Y. Zhang, J. Electroanal. Chem., 2016, 760, 158.

21. J. S. Do and T. C. Chou, Ind. Eng. Chem. Res., 1990, 29, 1095.

22. A. Trojánek, J. Langmaier, and Z. Samec, J. Electroanal. Chem., 2007, 599, 160.

23. M. S. Kilic, M. Z. Bazant, and A. Ajdari, Phys. Rev. E, 2007, 75, 021503 .

24. J. P. Veder, R. D. Marco, G. Clarke, R. Chester, A. Nelson, K. Prince, E. Pretsch, and E. Bakker, Anal. Chem., 2008, 80,6731

25. Y. Liang, J. Huang, P. Zang, J. Kim, and W. Hu, Appl. Surf. Sci., 2014, 322, 202.

26. R. Igreja and C. J. Dias, Sens. Actuators, A, 2004, 112, 291.

27. D. E. Yates, S. Levine, and T. W. Healy, J. Chem. Soc. Faraday Trans., 1974, 70, 1807.

28. V. V. Balladur, A. Theretz, and B. Mandrand, J. Colloid Interface Sci., 1997, 194, 408. 